\title{
INTRAOSSEOUS SYNOVIAL SARCOMA OF THE CALCANEUM
}

\author{
Vishnu Senthil ${ }^{1}$
}

${ }^{1}$ Resident, Department of Orthopaedics, Kasturba Medical College Manipal University, Manipal.

\section{ABSTRACT}

Synovial sarcoma is a malignant soft tissue tumour rarely involving the bone. We report a case of an intraosseous biphasic synovial sarcoma involving the calcaneum. A young adult presented with swelling of left foot with a healed sinus fixed to the bone. Radiological investigation showed the swelling was arising from the bone with infiltration of nearby tissue. No evidence of metastasis or skip lesions. Tissue diagnosis confirmed synovial sarcoma. Patient underwent below-knee amputation with adjuvant chemotherapy. Patient was on remission and later succumbed to the disease due to metastasis to lungs. Very few cases of primary intraosseous synovial sarcoma have been reported.

\section{KEYWORDS}

Intraosseous Variant, Synovial Sarcoma, Calcaneum,

HOW TO CITE THIS ARTICLE: Senthil V. Intraosseous synovial sarcoma of the calcaneum. J. Evolution Med. Dent. Sci. 2016;5 (54): 3702-3704, DOI: $10.14260 /$ jemds/2016/849

\section{INTRODUCTION}

Synovial sarcoma is a rare soft tissue sarcoma commonly arising from extremities presenting as para-articular lesions with calcification. Rarely synovial sarcoma presents as an intraosseous variant. We report a case arising from the calcaneum. To our best of knowledge intraosseous synovial sarcoma of calcaneum has not been reported before.

\section{CASE REPORT}

A 20-year-old male presented with a swelling of the left foot about three months ago. Swelling and pain was insidious onset and progressive till the present condition. On clinical examination, swelling, warmth, localised tenderness, and a healed sinus fixed to the underlying bone present. Atrophy of gastro soleus muscle. Movements of ankle were normal, but subtalar movements were restricted and painful. Dorsalis pedis and posterior tibial pulse were palpable. Blood investigations showed ESR-80 mm/hr and CRP-10 mg/L. Radiological examination revealed a lytic lesion in the calcaneum with increased soft tissue density [Fig. 1]. CT [Fig. 2] and MRI [Fig. 3] showed a lesion of dimension $7.6 \times 6.6 \times 6.0$ $\mathrm{cm}$ primarily involving the calcaneum with soft tissue infiltration. Differential diagnosis of osteomyelitis and Ewing sarcoma considered. Chest $\mathrm{x}$ ray and CECT chest revealed no metastasis. Patient underwent incisional biopsy. Histopathological examination of gross specimen and cut section showed yellow tan areas interspersed with haemorrhage and necrosis. Microscopic examination showed areas of spindle cell formation along with areas of rounded cells forming islands and cleft like vascular spaces suggestive biphasic intraosseous synovial sarcoma [Figure 4]. Immunohistochemical marker showed CD 99 positive, BCL-2 positive, CD 56, and EMA showed moderate sensitivity. S-100 weakly positive. Desmin and LCA were negative. Bone scan was negative except for calcaneum.

Financial or Other, Competing Interest: None.

Submission 27-05-2016, Peer Review 22-06-2016,

Acceptance 27-06-2016, Published 07-07-2016.

Corresponding Author:

Vishnu Senthil,

Kasturba Medical College,

Manipal University,

Manipal-576104.

E-mail: vishsnake@gmail.com

DOI: $10.14260 /$ jemds $/ 2016 / 849$
Patient counselled regarding the prognosis and underwent below-knee amputation. Intraoperative margins were negative in frozen section. Adjuvant chemotherapy regimen consisting 4 cycles of vincristine, adriamycin, cyclophosphamide, and Mesna with three weeks interval. After three months, patient developed breathlessness and pleural effusion. CECT chest showing few small well defined soft tissue density nodules randomly scattered bilaterally in lung parenchyma suggesting metastasis [Fig. 5]. Patient was advised further chemotherapy, but was discharged under request in view of financial constraints. Patient later succumbed to the disease in two weeks.

\section{DISCUSSION}

Historically, synovial sarcoma, which was believed to arise from synovial cell, but with advancements in molecular genetics. It was found to arise due to a recurrent chromosomal translocation $[\mathrm{t}(\mathrm{X} ; 18)(\mathrm{p} 11 ; \mathrm{q} 11)]$ forming a fusion protein. ${ }^{1}$ It accounts about $7-10 \%$ of soft tissue sarcoma affecting adolescents and young adults. Tumour frequently arises around large joints mainly knee, but occurrence in other sites like head and neck, trunk and abdomen are not uncommon. Only $20 \%$ of the cases show invasion of the underlying bone. Synovial sarcoma arising from bone is rare and only few cases have been reported till date.2,3

Our patient had a primary bone involvement with soft tissue infiltration. No evidence of any other lesion confirmed with bone scan favoured our diagnosis. Microscopy showing spindle cells and round cells with increased mitotic figures and further positive IHC markers confirmed our diagnosis.

Treatment guidelines consist of locoregional control with adjuvant chemotherapy and radiotherapy. Lewis et al. quoted that despite local wide excision of tumour with negative margins, there is $40 \%$ chance of metastasis. 4,5

Peculiar location of this lytic lesion in the foot with a healed sinus was considered and treated as osteomyelitis in a primary health care centre and was referred to our institute due to lack of improvement in his clinical condition. Patient underwent debridement and biopsy. Synovial sarcoma was confirmed by biopsy and IHC. Poor prognosis explained to our patient because the initial size of lesion was greater than $5 \mathrm{~cm}$ with adjacent soft tissue involvement. ${ }^{6}$ 
Confusion in presentation also added to delay in treatment. Patient succumbed to metastasis despite initial good locoregional control.

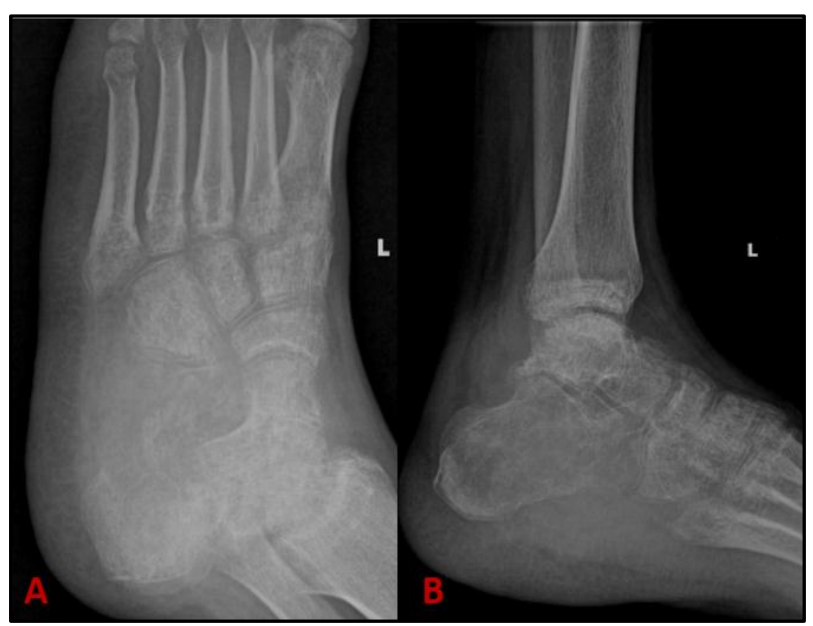

Fig. 1

Radiograph of left foot anterior-posterior [A] and Lateral [B] view showing lytic lesion in the calcaneum with increased soft tissue shadow. Osteoporosis of talar and metatarsal bones present.

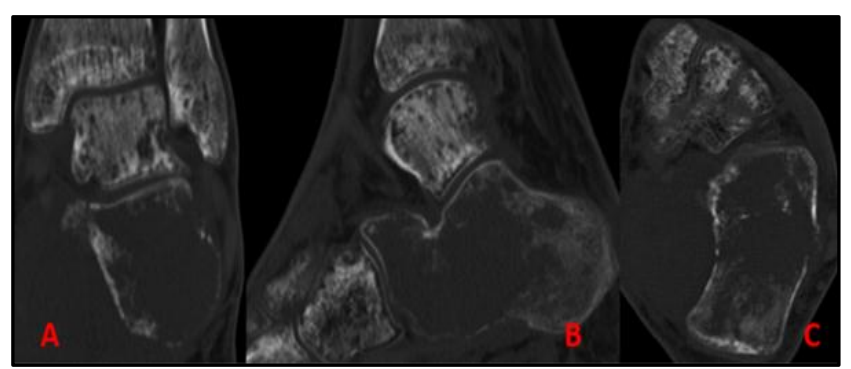

Fig. 2

CT scan of left foot sagittal [A], coronal [B], and axial [C] section showing lytic lesion in the calcaneum with cortical breech and soft tissue infiltration.

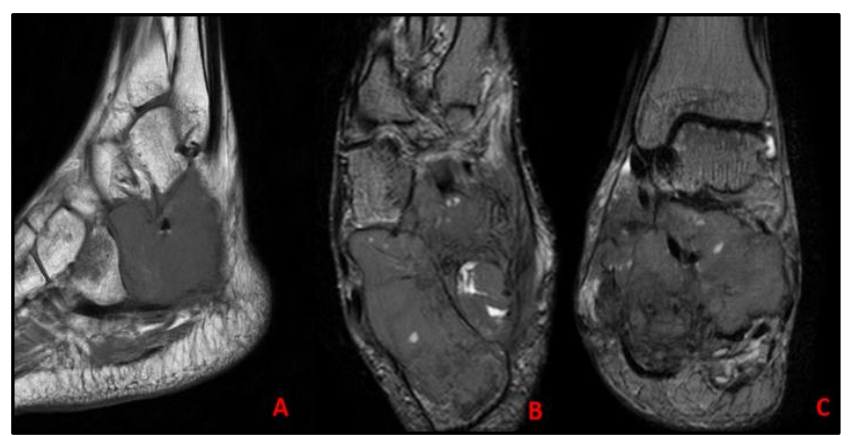

Fig. 3

MRI section coronal [A], Axial [B], and sagittal [C] showing $\mathrm{T} 1$ weighted images with post contrast enhancement. 7.6 × 6.6 $\mathrm{x} 6.0 \mathrm{~cm}$ lesion is seen involving the calcaneum and adjacent soft tissue extension. No extension into the ankle or sinus tarsi.

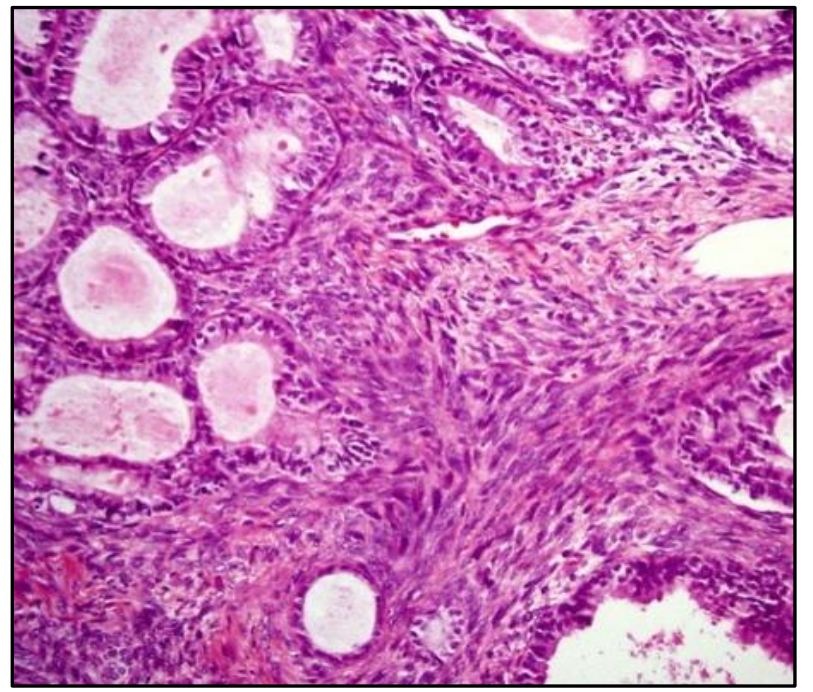

Fig. 4

Microscopic section showing interlacing fascicles of spindle cells with scant cytoplasm. Few areas with rounded cells forming islands surrounded by fibrocollagenous stroma and few cleft like (Hemangiopericytoma) vascular spaces.

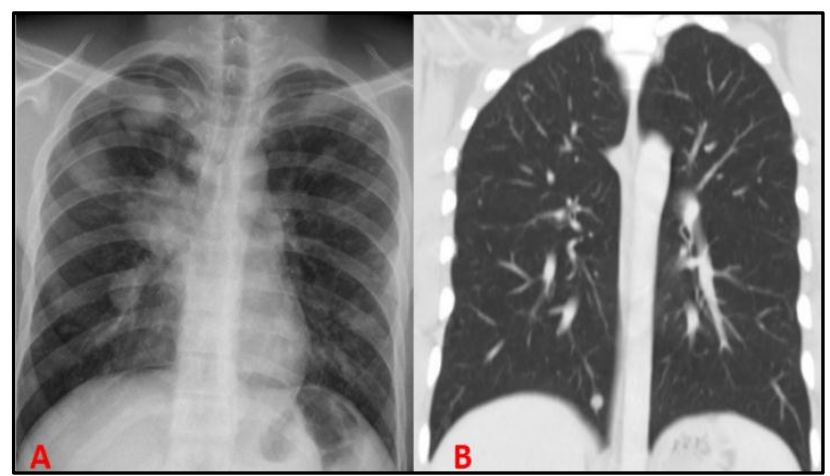

Fig. 5

Radiograph of chest posterior-anterior view [A] and CECT chest [B] showing well-defined soft tissue density nodules randomly scattered in both lung parenchyma.

\section{CONCLUSION}

Awareness of intraosseous synovial cell sarcoma and its poor prognosis is needed among orthopaedic surgeons and pathologist because this tumour can present in uncommon sites and mimic common infective pathologies leading to delay in treatment. Biopsy and culture of all lytic lesions should constitute an integral part of treatment protocol.

\section{REFERENCES}

1. Naka N, Takenaka S, Araki N, et al. Synovial sarcoma is a stem cell malignancy. Stem Cells 2010;28(7):1119-31.

2. Zulkarnaen M, Pan KL, Shanmugam PS, et al. Intraosseous synovial sarcoma of the proximal femur. Malaysian Orthopaedic Journal 2012;6(1):49-52.

3. Beck SE, Nielsen PG, Raskin KA, et al. Intraosseous synovial sarcoma of the proximal tibia. Int J Surg Oncol 2011;2011:184891. 
4. Lewis JJ, Antonescu CR, Leung DH, et al. Synovial sarcoma: a multivariate analysis of prognostic factors in 112 patients with primary localised tumours of the extremity. J Clin Oncol 2000;18(10):2087-94.

5. Liu Z, Jin S, Fu S, et al. Management of the primary intraosseous synovial sarcoma of the jaws: be careful of the surgical margin. J Oral Maxillofac Surg 2015;73(3):550-63.
6. Hiraga H, Nojima T, Isu K, et al. Histological and molecular evidence of synovial sarcoma of bone. A case report. J Bone Joint Surg AM 1999;81(4):558-63. 